DOI: 10.14526/2070-4798-2019-14-4-97-102

\title{
Methodical approaches to aerobic productivity formation among qualified weightlifters
}

\author{
Radmir V. Samigullin* \\ Ulyanov State Pedagogical University, Ulyanousk \\ Ulyanovsk, Russia \\ ORCID: oooo-ooo1-6541-769X, r.samigullin1986@yandex.ru*
}

\begin{abstract}
Kettlebell lifting is one of the youngest kinds of competitive activity. It is interesting for the athletes owing to its availability, support on national traditions. The exercises with kettle balls provide organism development, its functions harmonization, self-actualization and selfdevelopment of a personality. Materials. The article presents the problem of an individual motor rhythm formation as one of the leading factors of technical mastery improvement in qualified weightlifters. Research methods. Information sources and normative documents analysis and summarizing, pedagogical experiment, testing mathematical handling of research results. Results. The methodology of an individual rhythm formation and the conditions of its mastering are created. One of the main conditions is the model of rhythmic movements creation. They are included into the structural content of techniques. If an athlete understands the rhythmic base of each difficult motor action it helps to distribute rationally muscle efforts, alternate tension of the working muscles with relaxation, successfully orient oneself in spatio-temporal and spatio-power parameters of motor act, the periods and phases of the mastered techniques. Conclusion. The results of the pedagogical experiment showed the necessity to form an individual motor rhythm. It provides competitive actions effectiveness increase, easiness and freedom of movements improvement, the satisfaction level with the training process increase.

Keywords: kettlebell lifting, aerobic component, methodology, pedagogical experiment.
\end{abstract}

For citation: Radmir V. Samigullin*. Methodical approaches to aerobic productivity formation among qualified weightlifters. Russian Journal of Physical Education and Sport. 2019; 14(4): 82-86. DOI: 10.14526/2070-4798-2019-14-4-97-102.

\section{INTRODUCTION}

High level of working capacity among those, who go in for kettlebell lifting, their training and competitive activity effectiveness increase are achieved in case of timely oxygen provision for the active muscles and physiological systems. A purposeful development of speed-power oriented qualities among qualified weightlifters, taking into account the specificity of this kind of sport, is more effective in case of creating aerobic conditions in the working muscles. This problem solution demands the corresponding means and methods of sports training use, the diversity of which together with special respiratory exercises provides coordinating processes improvement -an important factor of muscle power indices increase.

The aerobic productivity increase in qualified weightlifters under the influence of the speed-power oriented character exercises, fulfilled in favorable natural conditions, leads to MOC (maximum oxygen consumption) increase, achieving maximum values at the competitive stage of sports training. The results of the pedagogical experiment showed that almost in terms of the same level of physical and technical readiness of those, who go in for kettlebell lifting, higher results were in the athletes with better aerobic abilities. During power oriented exercises of big and moderate power the main condition of high working capacity and competitive activity effectiveness, in the opinion of the leading scientists, is organism provision with oxygen [2, 4, 7]. It makes the topic of this research work extremely urgent.

The aim of the research work is theoretical and experimental importance substantiation of aerobic productivity improvement in those, who go in for kettlebell lifting.

\section{MATERIALS AND METHODS}

In order to check the effectiveness of created by us methodology of aerobic productivity increase in qualified weightlifters we held the pedagogical experiment. 24 athletes of the IInd and 
the Ist category at the age of 17-19 took part in the experiment. Control group (CG) and experimental group (EG) included 12 athletes each. In the CG the training process was realized in accordance with the program of qualified weightlifters sports training, recommended by the Russian Federation weightlifting federation. In the EG we used the methodology, created on the basis of the aerobic productivity increase method in those, who go in for kettlebell lifting.

Before the pedagogical experiment we held the test in order to reveal the initial level of athletes' physical and technical readiness in both groups. In order to define physical readiness we used the following control exercises: shuttle running 3x10 $\mathrm{m}$ (s), 30 meters running (s), standing long-jumps; chin-up (quantity), 1000 meters running (min). Technical training was estimated by the group of experts, qualified specialists in kettlebell lifting (5-point system), according to the following tests: individual motor rhythm formation level; rational distribution and re-distribution of muscle efforts; an optimal initial position during kettle balls lifting.

Research materials analysis didn't reveal considerable differences in the level of physical and technical readiness of weightlifters from CG and EG ( $>0,05)$. In the EG great attention was paid to aerobic and anaerobic exercises fulfillment. Running exercises included the following: cross-country running, hills running for different altitude; running the hill down - in single file, with the tempo of running steps change; running on the grass, during warm season - on water at a the average depth; moving forward on two legs using jumps, triple, fivefold and tenfold jumps fulfillment - provided coordination of movements and respiratory rhythm improvement.

Motor objectives fulfillment in different picturesque places provided psycho-emotional state improvement. Competitive method use during 30 and 60 meters running from a low and high start on different surface; competition for more qualitative special running exercises fulfillment helped to form the state of satisfaction with the training lessons.

Muscle power development was realized by us according to two directions:

I -using the methods of extensive influence, which provides power oriented exercises fulfillment with the weight, which is from 60 to $70 \%$ from maximum, with gradual increase of muscle tension till maximum one.

II -the use of intensive influence methods, during which insignificant weights were fulfilled with several repetitions and gradual speed of movements increase.

Motor structure of kettle balls pushing techniques using both hands from chest and a spurt has a difficult content, conditioned by the combination of differently directed movements with different nervous-muscular tension $[1,3,6]$. This demands timely muscle efforts distribution and redistribution, rational motor rhythm mastering. Their fulfillment is accompanied by considerable efforts of respiration and blood circulation functions, the amount of the incoming blood decrease to the physiological organs; the activity of kidneys, digestive system suppression. In this case it is important to take into account the peculiarities of changes. They happen in the activity of the providing systems: cardiovascular, respiratory system and others. In kettlebell lifting the amount of oxygen consumption is determined by the need not only for the working barred muscles, but also cardiac muscle and the muscles, which provide lungs ventilation.

In terms of the tempo increase of the training tasks with dumbbells fulfillment or their weight increase the organism demands great amount of oxygen. Breathing tempo increases weight lifting with insufficient movements coordination or during their irrational motor rhythm, which decreases the efficiency of muscle work of muscles activity, which are not used during techniques fulfillment. It makes the problem of aerobic productivity increase among qualified weightlifters (17-19 years old) a prospective direction of their sportsmanship improvement.

One of the leading factors, which provide working capacity of athletes, are aerobic abilities, defined according to the indices of maximum oxygen consumption (MOC).During sub-maximal and maximal training loads fulfillment high working capacity and the effectiveness of competitive activity increase happen owing to timely oxygen provision for the working muscles. Maximum oxygen consumption, according to the research works by 
N.V. Zimkin and others, 2007, happens in terms of heart rate $170-80$ beats $/ \mathrm{min}$.

In kettlebell lifting with the level of physical and technical readiness increase there is the duration increase of power oriented exercises fulfillment. At the same time, their structural content should correspond with the characteristics of the competitive actions structure. During maximum muscle load fulfillment special importance for motor activity energy supply have aerobic and anaerobic components. Well developed capillary network, the increased amount of mitochondria, myoglobin, the increased activity of oxidative enzymes help to slow muscle fibers use aerobic way of adenosine triphosphate (ATP) resynthesis. Quickly contracting oxidation-glycolutic muscle fibers (II A type) are characterized by the combination of quick and slow fibers. It gives an opportunity to use both aerobic and anaerobic ways of ATP resynthesis [5, 7].

During cyclic training load fulfillment, which is more than two minutes, aerobic way of energy supply prevails over anaerobic one. With special endurance indices increase there is the number of capillaries increase of the working muscles. Endurance development provides the efficiency of the muscles work improvement and the effectiveness of an athlete's motor potential realization.

With the training level and qualification increase there is a weightlifter's efficiency of motor actions increase. It is connected with more active coordination of the muscles work. Owing to this their working capacity at the final phase of a motor act considerably increases. The effectiveness of an organism aerobic abilities is demonstrated by heart rate increase (HR) till 140-160 beats/min in terms of continuous motor activity from 10- 15 minutes till 2,0-2,5 hours. In terms of lower HR indices the training work doesn't provide mobilization of oxygen-transport system activity. HR indices increase more than 160 beats/min conditions anaerobic mechanisms involvement, byproducts accumulation in muscles, the volume of motor activity decrease $[2,4,10]$.

Aerobic and anaerobic organism productivity indices improvement and effectiveness of the athlete's competitive activity was provided by interval hypoxic training. Positive influence of the anaerobic regimen of the training load in kettlebell lifting is in cardiovascular system work improvement, owing to local character of the influence, and in higher effectiveness of physiological systems functioning.

The leading role of aerobic component is in cardio-respiratory system strengthening by means of cross-country running, skating, skiing with different lifts and slopes inclusion into the content of the training process. These kinds of the training load provide coronary vessels lumen; blood circulation increase; oxygen provision for myocardium [1,5, $7,11]$. Sprint and average distance running creates necessary conditions for morpho-functional changes in physiological systems; provides general endurance, aerobic productivity indices increase and organism development.

Speeding-ups from a low and a high start, from the spot stimulate quickness of movements improvement, muscle power and anaerobic capacities of the athlete increase. In case of anaerobic productivity increase there is maximum level of oxygen consumption increase; there is the ability development to preserve the achieved indices during the whole time of competitive exercises fulfillment; and also respiratory processes activation. Aerobic and anaerobic sports training means combination creates more comfortable conditions for functional system adaptation to new kinds of muscular load.

Respiratory exercises of special orientation provide oxygen for cardio-vascular and other physiological systems, strengthening of which is a necessary condition for motor working capacity increase and a weightlifter's positive psychoemotional state preservation. An optimal ratio of power oriented exercises with cyclic ones, which increase aerobic processes in terms of favorable natural conditions, provided physical readiness indices improvement among people, who go in for kettlebell lifting.

Thus, the main methodical approaches to aerobic productivity formation among qualified weightlifters are the following: the use of interval hypoxic training; cyclic exercises in different difficult natural conditions use during the training; speeding-ups use at short parts from different initial 
positions and others.

\section{RESULTS AND DISCUSSION}

After the pedagogical experiment we organized additional testing, which helped to reveal the dynamics peculiarities of physical and technical readiness indices among the weightlifters from CG and EG. The experimental results analysis showed that systematic training loads provided technical readiness results improvement in both groups: $\mathrm{CG}$ and EG. However, in the EG the results increase was considerably higher. In CG with the initial results of an individual motor rhythm formation 2,70 $\pm 0,19$ points to the end of the pedagogical experiment the indices improved till $3,11 \pm 0,21$ points ( $p>0,05$ ); in the EG with the initial results $2,69 \pm 0,15$ points to the end of the pedagogical experiment the results

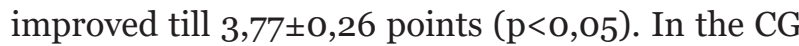
with the initial results of a rational distribution and redistribution of muscle efforts $2,81 \pm 0,14$ points to the end of the pedagogical experiment the indices increased till 2,94 $\pm 0,21$ points ( $p>0,05$ ); in the EG with the initial results $2,79 \pm 0,20$ points to the end of the pedagogical experiment results increased till $3,32 \pm 0,27$ points $(\mathrm{p}<0,05)$. The same tendency of technical readiness indices improvement among the weightlifters from EG was revealed according to other control exercises.

Physical readiness indices also improved in both groups, however, with evident predominance of the weightlifters from the EG. With the initial results $11 \pm 0,36$ seconds in 30 meters running in the $\mathrm{CG}$ to the end of the pedagogical experiment the indices improved till 4,92 $\pm 0,24$ seconds ( $p>0,05$ ); in the EG with the initial results 5,14 $\pm 0,29$ seconds to the end of the pedagogical experiment the results increased till 4,59 $\pm 0,35$ seconds ( $p>0,05)$. In the CG with the initial results in chin-up from hanging position at the bar $17,19 \pm 0,81$ times to the end of the pedagogical experiment the indices increased and were19,38 $\pm 0,95$ times, $(p>0,05)$; in the EG with the initial results $17,06 \pm 0,69$ times to the end of the pedagogical experiment the results increased

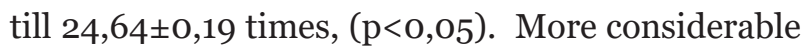
indices increase in the EG was revealed according to other tests, which characterize physical readiness.

\section{CONCLUSION}

Thus, the results of the pedagogical experiment showed, that owing to aerobic productivity increase among qualified weightlifters by means of rational alternation of different intensity training loads, running exercises use, cross-country and mountains long-distance running and other means use in the EG there was considerable physical and technical readiness indices improvement. It proves the expediency of athletes' attention paying to cardio-respiratory system strengthening, which gives oxygen to physiological systems. An individual motor rhythm formation in kettlebell lifting provides an athlete's technical readiness development. Owing to motor rhythm all structural components of sports activity take part in specially organized training process with a clear rhythm, there appears an optimal ratio of the parts of a motor act, continuity and smoothness of movements, which provides efficiency, freedom and easiness of a difficult technique fulfillment.

\section{REFERENCES}

1. Anurov V.L. Kettlebell lifting in physical upbringing of students of higher educational establishment. Candidate's thesis. Moscow. 2008: 23.

2. Borisevich S.A. Training process organization among athletes-weightlifters of high qualification. Candidate's thesis Omsk. 2003; 24.

3. Gomonov V.N. Technical training individualization among athletes-weightlifters of different qualification. Candidate's thesis. Smolensk. 2000; 24.

Dobrovolskiy A.S. Girevoj sportivnyj ryvok giri: uchebno-metodicheskoe posobie [Weight sports dumbbells start: methodical manual]. Rostov-onDon. 2014: 40 (In Russ.).

Zimkin N.V. Fiziologiya cheloveka: uchebnik dlya institutov fizicheskoj kul'tury [Human physiology: textbook for physical culture Institutes]. Moscow: "Physical culture and sport". 2007: 496. (In Russ.)

Kozitskiy D.M. Tehnicheskaya podgotovka, kriterii ocenki tehniki dvizhenij $v$ girevom sporte: uchebno-metodichekoe posobie [Technical training, evaluation criteria of movements technique in kettlebell lifting: methodical manual]. Cheboksary. 
2009; 114 (In Russ.).

Nazarenko L.D. Fiziologiya fizicheskih uprazhnenij [Physiology of physical exercises]. Ulyanovsk: "UlSPU named after I.N. Ulyanov". 2019: 262 (In Russ.).

4. Samigullin R.V., Nazarenko L.D., Timoshkin V.V. Techniques modeling in kettlebell lifting. Pedagogiko-psihologicheskie I medikobiologicheskie problemy fizicheskoj kul'tury I sporta = The Russian Journal of Physical Education and Sport. 2018; 13(3): 66-74. DOI 10.14526/20704798-2018-13-3-66-74 (In Russ., In Engl.).

5. Simen V.P. The ways of weightlifter's technical training effectiveness increase. Candidate's thesis. Cheboksary. 2004: 22.

6. Simen V.P. Girevoj sport I metodika ego prepodavaniya: uchebnoe posobie [Kettlebell lifting and the methodology of its teaching: manual]. Cheboksary: CSPU named after I.Y. Yakovlev. 2002: 107 (In Russ.).

7. Ryabchuk A.V. Adaptive changes of the functional state during going in for kettlebell lifting among cadets of military Institute. Candidate's thesis. Tyumen. 2012: 23.

8. Raab M. Decision making in sports: Influence of complexity of implicit and explicit learning. International Journal of Sport and Exercise Psychology. 2003; 1: 310-337.

9. Shima K., Tanji J. Neuronal activity in the supplementary and presupplementary motor arears for temporal organization of multiple movements. Journal of Neurophysiology. 2000; 84: 2148-2160.

10. Williams A.M., Hodges N.J. Practice, instruction and skill acquisition in soccer: challenging tradition. Journal of Sports Sciences. 2005; 23: 637-650.

11. Williams A.M., Ward P. Developing perceptual expertise in sport. Expert Performance in Sports: Advances in Research on Sport Expertise. 2003: 219-250.

\section{Submitted: 10.11.2019}

\section{Author's information:}

Radmir V. Samigullin - Post-graduate, Ulyanov State Pedagogical University, Ulyanovsk, 4327oo, Russia, Ulyanovsk, Square of the 10o ${ }^{\text {th }}$ anniversary of Lenin's birth, House 4, e-mail: r.samigullin1986@ yandex.ru 